DOI: $10.17148 /$ IARJSET.2021.8935

\title{
Use Of Ethnomedicinal Plants To Overcome Paracetamol Toxicity
}

\author{
Meena Jha $^{1 *}$, Asita Elengoe ${ }^{2 *}$ \\ 1* Researcher - Biotechnology Department, Science Faculty, Health Sciences, Lincoln University College, Malaysia \\ ${ }^{2 *}$ HOD, Biotechnology Department, Science Faculty, Lincoln University College, Malaysia
}

\begin{abstract}
Maintenance of good health by active and intelligent lifestyle by citizens helps to build great nation. Good health is the biggest source of happiness. Wellness is the holistic approach of physical mental, social, emotional and spiritual fitness. We have to work on this beautiful life by taking little steps. These small steps can make our planet healthy. Many people think that investing in gyms and use of other sports instruments will make them fit and healthy. Consuming balanced diet rich in fruits vegetables can ward off many diseases. A healthy and positive lifestyle increases the longevity of human beings. But due to tech-savvy life we all need immediate results for curing ourselves so nowadays people are more dependent on medications for remaining healthy. Its true that medicines give instant cure but we should not overlook or ignore the side effects of these synthetic medications. Paracetamol is renowned painkiller used by people worldwide to cure aches and pains. It is available in various brand names like Calpol, Tylenol, Dolo 650 etc. Regular or prolong use may result in dizziness, fast heartbeat and may even results in liver toxicity. Most of us are totally unaware of pharmacodynamics of Paracetamol. So people consume it even without prescription by physicians. Ethnomedicinal plants are easily available and contribute in our well-being as they contain specific bioactive compounds, dissolved alkaloids and are eco-friendly, biodegradable and easier to use. Since ancient times they are used for treating diseases and many chronic ailments. Black Pepper, Ginger, Basil, Mint, Fenugreek, Green Tea leaves, Turmeric, Eucalyptus, Lemon Grass etc are ethnomedicinal plants which can easily overcome Paracetamol toxicity. This study is conducted on rural people of South India. Out of 116 respondents 55.2\% of people believed that prolonged usage of Paracetamol may result into liver toxicity whereas $45.7 \%$ of rural people are using plant based medications like roots, rhizomes, juices of flowers to cure fever, aches and pains.

But latest study also reveals that Industrial revolution, deforestation, desertification has polluted and damaged environment.1.6 billion people are dependents on forests $74 \%$ people are affected due to land degradation. Sustainable management is compulsory. Forest management is necessary by planting and saving biodiversity. Working with endogenous people and local community can help us to switch over to plant based medications. We all should affirm that each one should plant one. We need to think globally for saving lives. Saving endangered plants and animals are very important for all of us. Insects, birds are pollinators which help to grow many medicinal plants. Birds and animals droppings helps in seed dispersal. Example cutting of strings of facemask before disposal can help to reduce fatality of birds. These strings coils in beaks and wings of birds which is actually harming birds. Let's be a change maker and protect our flora and fauna. Reiteration of good deeds is needed for all practices. Celebration of Tree Plantation, or birthday of Trees is must to save ecosystem. Let's together protect, promote and restore this planets plants and biodiversity. By sustainably managing wildlife and conservation of forests and medicinal plants, by combatting habitat loss, stopping desertification and reversing land degradation we can put a full stop to biodiversity loss. The study shows that proper use of ethnomedicinal plants can overcome Paracetamol toxicity because plants possess effective antioxidants and important alkaloids in them. We need to promote awareness from local folklore to global sectors for the effective usage of plants. This is scientific study based on experimentation and application which should help everyone across the countries for maintaining health. Indeed education can make differences and has the power to transform our lives.
\end{abstract}

Keywords: Ethnomedicinal plants; Pharmacodynamics; Biodiversity

\section{INTRODUCTION}

Staying fit and healthy is the greatest need of hour. Good health is the fundamental aspect of our life. But for keeping themselves healthy, people are more dependent on synthetic drugs. For quick results and instant relief people are more dependent on synthetic drugs. In 1960, Paracetamol toxicity was first noted and now this drug is commonly used in curing aches and pains, which may cause self-poisoning and has increased the deathrates. It is widely available for purchase without prescription and recommendation, so it must be given to legal status to medicine only to be used in prescription. The overdose and excess use of paracetamol may be injurious in long term.[1] Green plants are oldest source of many medicines. Fossil records states the uses of these medicines. [2] Some ethnomedicinal plants like Basil(Tulsi), Periwinkle 


\section{DOI: 10.17148/IARJSET.2021.8935}

(Sadabahar), Aloe vera (Ghritkumari), Ginger, Careya, Onion, Garlic, Curry leaves, Hibiscus, Turmeric(Haldi) are used in medicinal purposes to treat many diseases. These plants are very useful in the field of medicines. [3] These plants are also useful in making good indicators in many acid-base titrations for making natural dyes, soaps, perfumes etc.[4] Many plant parts are used to cure constipation, aches, pains, stomach ache, vomiting etc because ethnomedicinal plants consists of bioactive compounds like alkaloids, saponins, glycosides, carbohydrates, mucilage ,gum- resins, proteins, tannins. [5] These Plants used in since ancient times to cure innumerable ailments. They contain very important bioactive compounds[6] But the knowledge of usage of these medicinal plants are confined to local areas of forest areas and are orally informed to youngsters.[7] Nevertheless, the need of the hour is to raise more awareness through documentation of traditional wealth for treating distinguish diseases. [8] The pharmacognostic study reveals that medicinal plants are very effective to cure many diseases and they can replace and minimise the dependency on synthetic drugs. Study reveals that extract of Allium sativum can lower down the bad cholesterol and lipid profile of patients. [9] It also shows that the significant usages has antioxidant effect on body to reduce toxicity of liver. Hence, information and experimentation of ethnomedicinal plants confirms the important therapeutic factors. The loss of many plant species due to human activities and extinction could be the major concern and we have to conserve and protect our natural wealth.[10]

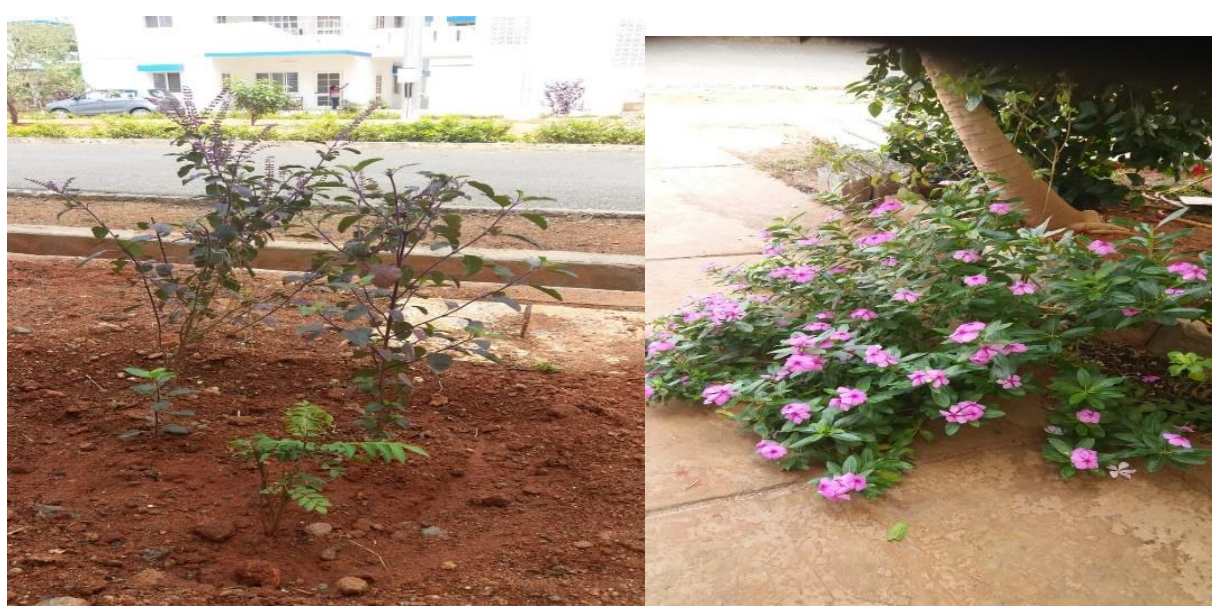

(a) Ocimum tenuiflorum (Tulsi, Basil)

Fig.(i). Ethnomedicinal Plants:

(b) Catharanthus roseus Periwinkle(Sdabahar)

\section{FOCUS OF THE STUDY}

The main intention of this study was to endow an overview and encourage maximum usage of the ethnomedicinal properties and application of these plants and to find the strength of reducing Paracetamol usage to prevent severity. The knowledge gaps should have to be get filled and more emphasis to improve further research should be focussed.

\section{METHODOLOGY \& DATA ANALYSIS}

Due to Pandemic lockdown, the online survey study was done and total of one hundred sixteen participants responded. The survey questionnaire was about the usage of ethnomedicinal plants for curing ailments instead of being dependent on synthetic drugs. The study was done between the month of February 2021 to July 2021 in Dehradun, India. Various types of questions like case-study based question, Assertion-Reason, Multiple choice questions, High order thinking skills questions were framed in Google form and were distributed to respondents via Gmail, Telegram, WhatsApp and other social sites. Interview of medical practitioner were taken telephonically regarding their prescription of painkillers to patients. The plant samples were collected and were dried to make herbarium for detailed study. The parts of plants like bark, juices, leave extracts, rhizome were grinded in electric grinder and were given to few patients suffering from fever and miraculous results were observed. 


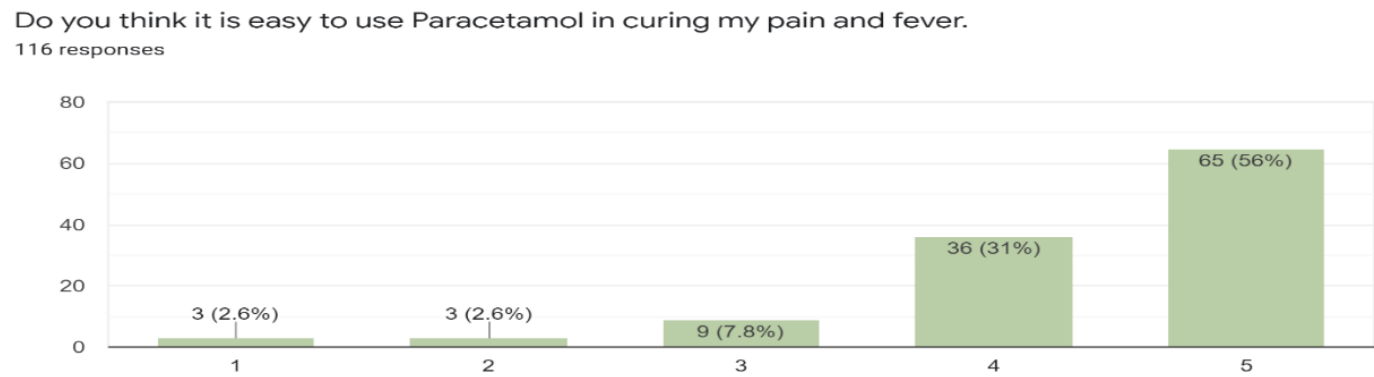

Fig (ii): This graph shows that $56 \%$ of people are using Paracetamol for medications.

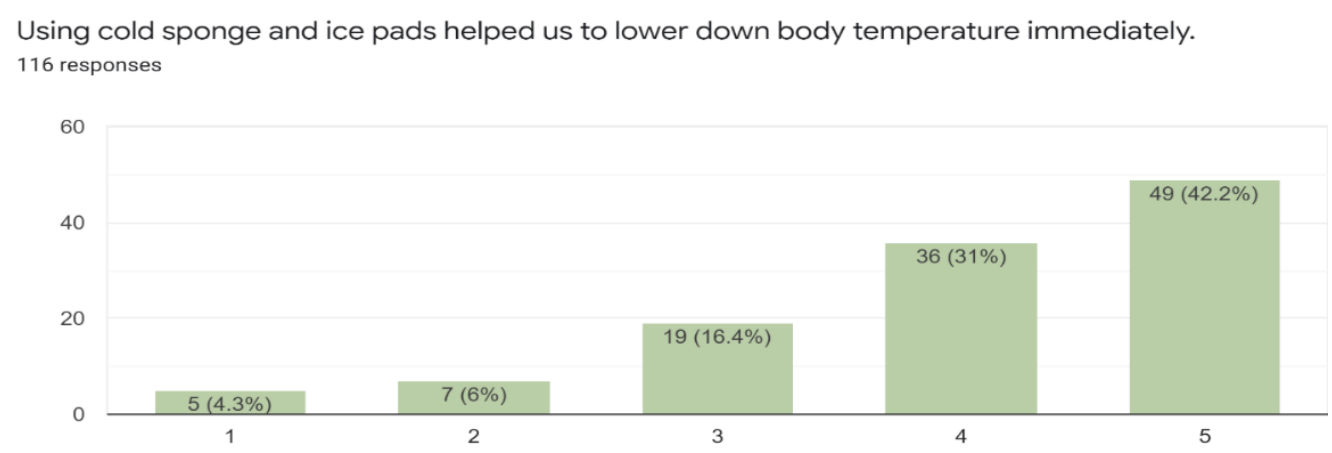

Fig (iii) : This graph shows that $\mathbf{4 2 . 2 \%}$ of people are using cold sponge to lower down body their temperature during fever.

\section{[2-(2,6-Dichloroanilino) phenyl] acetic acid is the IUPAC nomenclature of which drug?}

116 responses

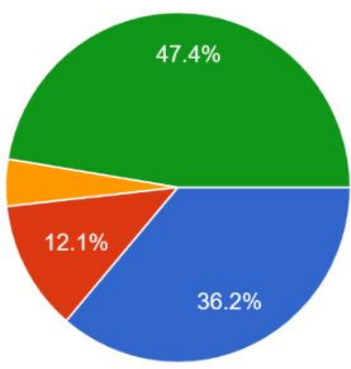

Fig (iv): This pie chart shows that only $47.4 \%$ of people knows the IUPAC name of Paracetamol.

The knowledge and usage are vast about natural medications in local areas, but all people are not aware in our country, even the Arabs have used and introduced many plants from India for treatment.[11] So all herbal medicines should be tested and experimented to encounter the medical challenges. Strong medicines must get replaced by natural ways.[12] the pharmacological study and more clinical experimentation and formulation of ethnomedicinal plants are required for effective implementations.[13] Rapid deforestation, industrialisation, overgrazing and threat to environment has caused immense loss of medicinal plants, Therefore, Sustainable Agriculture practices and domestications are the alternatives to maintain the germplasm of these precious plants.[14] To understand the phylogenetic tree and for qualitative study the sequences of DNA need to be decoded, so plant conservation must be given prior importance.[15] One must remember 


\section{International Advanced Research Journal in Science, Engineering and Technology}

\section{Vol. 8, Issue 9, September 2021}

\section{DOI: 10.17148/IARJSET.2021.8935}

medicinal plants are our indispensable natural assets which need to be judiciously used and protected for future. [16] We have to increase and spread the traditional knowledge of basic usage of plants from local folklore to the world for sustaining happy, healthy life.[17] More Gardening, Tree plantations, preservation of dried leaves and inflorescence in herbarium must be encouraged and taught to students for detailed study and further researches. [18]

\section{RESULTS AND DISCUSSION}

The findings of survey states that, in order to save money, time and due to lockdown most of the participants were doing self-medications to cure fever, aches and pains. These self -medications may be the major threat to vital organs like liver, kidneys, heart. However, many of respondents cannot deny the benefits of ethnomedicinal plants. 53 respondents out of 116 still believe the importance of medicinal plants for curing various ailments. Usage of rhizomes, roots, seeds, flower leaves, barks are common in few houses. Leaves juices, herbal tea etc are popular among residents of forest area. In many ancient literature the usage and importance of medicinal plants are mentioned. All the medicinal plants studied shows positive and effective results with zero side effects. Deforestation, Overgrazing, should be checked time ang again, more emphasise should be given to promote tree plantations drives, conservation of wild-life centuries and flora-fauna should be encouraged. More usage of ethnomedicinal plants and conventional knowledge should be promoted to minimize the toxicity produced by synthetic drugs.

\section{CONCLUSION}

All the Ethnomedicinal plants are having important bioactive compounds and they have immense potential to overcome Paracetamol toxicity because they have significant biological compounds for manufacturing medicines. People living in forests and rural areas are using these plant parts for their medications. In order to overcome the long term consequences and to minimise the toxicity of synthetic drugs we must conserve and use our forests judiciously. Sustainable developmental approach can help us to encounter the challenges.

\section{ACKNOWLEDGEMENT}

This is research study of author 1st, MJ. Sincere thanks to HOD Biotechnology, Research Supervisor guide, Lincoln University and Gratitude to Dehradun respondents \& all medical practitioners for sharing their wisdom.

Conflict Of Statement Of Interests: No one declared

\section{REFERENCES}

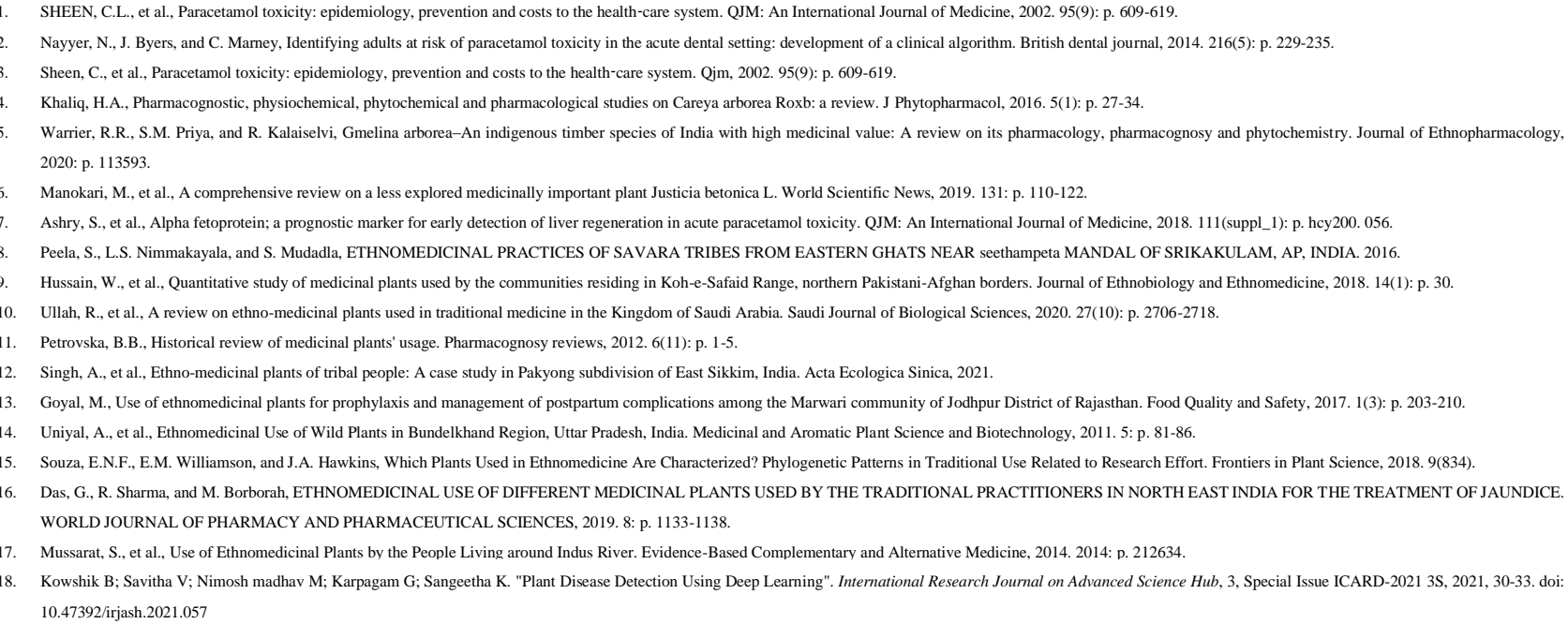

